\title{
Experimental study of mode transition characteristics of a cavity-based scramjet combustor during acceleration
}

\author{
Yu Meng ${ }^{\mathrm{a}, \mathrm{b}}$, Hongbin Gu ${ }^{\mathrm{b}, *}$, Jingheng Zhuang ${ }^{\mathrm{a}, \mathrm{b}}$, Wenming Sun ${ }^{\mathrm{a}, \mathrm{b}}$, Zhanbiao Gao ${ }^{\mathrm{b}}$, \\ Huan Lian $^{\mathrm{b}}$, Lianjie Yue ${ }^{\mathrm{b}}$, Xinyu Chang ${ }^{\mathrm{a}, \mathrm{b}}$ \\ a School of Engineering Science, University of Chinese Academy of Sciences, Beijing 100049, China \\ ${ }^{\mathrm{b}}$ Institute of Mechanics CAS, Beijing 100190, China
}

\section{A R T I C L E I N F O}

\section{Article history:}

Received 29 October 2018

Received in revised form 4 April 2019

Accepted 23 July 2019

Available online 26 July 2019

\section{Keywords:}

Scramjet combustor

Mode transition

Liquid kerosene

Acceleration

\begin{abstract}
A B S T R A C T
Experiments were performed in a direct-connect supersonic combustion test facility to simulate scramjet combustor acceleration in high altitude. The combustor inlet flow Mach number increased from 2.40 to 2.94, and the flowrate and total temperature simultaneously changed with Ma. The combustor has two cavities and fuel jets. The fuel used is room-temperature liquid kerosene RP3. Mode transition is seen to occur in the first cavity during acceleration, and pressure fluctuations occur in the transitions from both the ram mode to the transition mode and from the transition mode to the scram mode, indicating that the mode transition process is unstable. When the mode transition occurs upstream, the downstream ram mode has the effect of eliminating instability; therefore, the engine's overall thrust performance is stable. When the downstream is also in the transition mode, the thrust fluctuates, indicating that the mode transition is an unstable process.
\end{abstract}

(c) 2019 Elsevier Masson SAS. All rights reserved.

\section{Introduction}

Hypersonic air-breathing engines like scramjets show promise for applications such as hypersonic flight and space transportation because they offer high specific impulse and high payload ratio. A dual-mode scramjet operates in different modes for achieving high efficiency. The modes are identified from the precombustion shock train according to Billig's definition. In the ram mode, a normal shock train exists in the isolator; in the transitional mode, an oblique shock train is seen; and in the scram mode, no shock train is seen [1]. However, this categorization is not always possible for a cavity-based Scramjet combustor because it is difficult to obtain the full structure of the shock train. In this case, it is more convenient and accurate to use the mass average one-dimensional Mach number distribution method to identify the mode [2].

Studies have investigated the influencing factors [3-6] and control methods [7] of dual-mode supersonic combustors. Transition between the scram and ram modes is realized by changing the inflow condition, fuel scheme, and combustor design.

Sullins demonstrated mode transition when the combustor entrance temperature was varied from $T=1511-1705 \mathrm{~K}$. As simulated acceleration progressed, the combustor pressure rise became

\footnotetext{
* Corresponding author.

E-mail address: guhb@imech.ac.cn (H. Gu).
}

smaller than the separation pressure and the precombustion shock system was eliminated. This process seems very unsteady, and small variations in fuel flow can significantly affect shock train movement [8].

Micka and Driscoll [9] noted that a cavity-based combustor has two distinct combustion stabilization locations for different incoming flow temperatures. One is anchored at the leading edge of the cavity by heat release in the cavity shear layer, and the other is stabilized a short distance downstream of the fuel injection jet in the jet-wake. Yuan studied the effect of temperature and equivalent ratio on flame stability patterns and showed that the cavity shear layer stabilized the flame when the combustor operates in scramjet mode and jet-wake occurs when the combustor operates in ram jet mode [10].

Huang [11] analyzed various types of flame structures in dualmode scramjets. The cavity is widely used for flame stabilization in a dual-mode combustor because it offers advantages such as smaller additional drag force and total pressure loss. However, the cavity is limited by the combustor configuration, jet configuration, etc. [11-13]. Cai et al. [14] studied the influence of cavity geometry on mixing, flame stability, and ignition.

Fotia theoretically analyzed direct-connect ramjet-scramjet experiments and noted three configurations: facility loss limited region, negative entropy generation region, and normal shock compression limited region of unobserved operation. These instabilities 


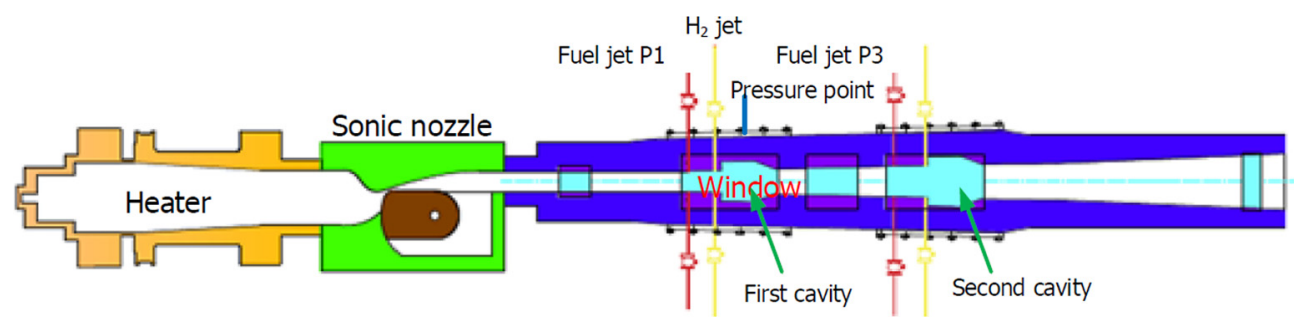

Fig. 1. Variable Mach number direct-connect supersonic combustor.
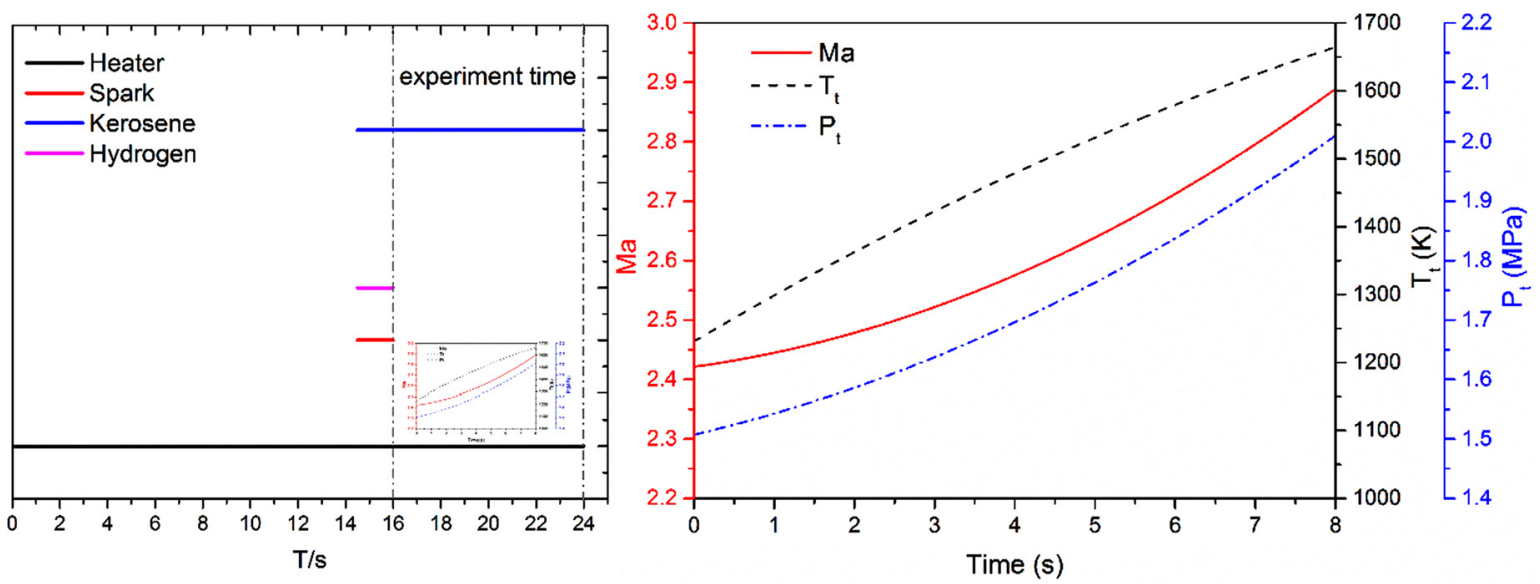

Fig. 2. Time sequence of the whole experiment (left); Inlet flow $M a / T_{t} / P_{t}$ changing with time (right).

may pose risks in terms of overall control of a vehicle powered by such an engine [15].

Zhang et al. [16,17] numerically and experimentally analyzed the pressure of ram-to-scram transition under continuously changing inlet flow Mach number. Kouchi and Mitani [7] numerically and experimentally obtained different modes by changing the fuel equivalence ratio under fixed Mach number and found that the mode transition jumps because of changes in the flame stability mode and flame propagation mode.

Most ground tests of mode transition only varied the equivalent ratio and other individual parameters [18]. In recent years, control of the mode transition of a dual-mode scramjet engine for achieving increased efficiency has become an important issue. Accurate mode transition requires flight experiments. Since 2006, the US Hypersonic International Flight Research Experimentation research program has studied dual-mode transition with hydrocarbon fuels through flight tests, ground experiments and computational fluid dynamics. Ignition, dual-mode operation, and stable transition from dual-mode to scram-mode operation were observed during flight experiments [19,20].

Mode transition depends on the inlet flow, heat release, combustor configuration, etc., and most previous studies used a ground-based fixed Mach number. The present study provides an experimental technique in which the flow Mach number, temperature, and flowrate on the ground can be changed continuously. Changing inlet flow parameters such as the velocity and dynamic pressure directly changes the coupling relationships among the fuel jet, heat release, and cavity. In this study, flame stability and its transition were studied by simulating flight curves.

\section{Experimental setup}

\subsection{Experimental facility}

Experiments were conducted using the variable Mach number direct-connect supersonic combustor of Institute of Mechanics Chinese Academy of Sciences. Fig. 1 shows a schematic diagram of the
Table 1

Inflow state under each experimental condition.

\begin{tabular}{lllll}
\hline Time $(\mathrm{s})$ & Ma & $\mathrm{T}_{\mathrm{t}}(\mathrm{K})$ & $\mathrm{P}_{\mathrm{t}}(\mathrm{MPa})$ & Flow $(\mathrm{kg} / \mathrm{s})$ \\
\hline 0.0 & 2.4 & 1228 & 1.47 & 1.795 \\
2.0 & 2.5 & 1363 & 1.57 & 1.683 \\
4.0 & 2.6 & 1493 & 1.55 & 1.417 \\
7.0 & 2.8 & 1591 & 1.66 & 1.249 \\
8.0 & 2.9 & 1686 & 1.98 & 1.076 \\
\hline
\end{tabular}

experimental bench. The heater combusts air, hydrogen, and oxygen, and the oxygen mole fraction is $21 \%$ after combustion. The Mach number at the nozzle can be varied from Ma 1.7 to 3.2 by using a rotating cam structure. The combustor inlet total temperature and flowrate are changed by varying the hydrogen, oxygen, and air flowrates. In this test facility, the valve of gas and nozzle can be controlled, and data are acquired using an automated control and data acquisition system in experiment. Fig. 2 (left) shows the time sequence of experiment. From $16 \mathrm{~s}$ to $24 \mathrm{~s}$ is the effective experimental time, when inflow Ma, $\mathrm{T}_{\mathrm{t}}$, and $P_{\mathrm{t}}$ changing with time. Before $14 \mathrm{~s}$ is the heater preparation time, and 14.5 to $16 \mathrm{~s}$ is ignition time.

Fig. 2 (right) shows the continuous change in the Mach number at the combustor inlet. Table 1 shows the inflow states, where $T_{t}$ is the total temperature; $\mathrm{P}_{\mathrm{t}}$, the total pressure; and Flow, the inlet flowrate. The total pressure is measured by the pressure sensor in real time. The total temperature is calculated by the flow of gas into the heater. The Mach number is calculated by the total temperature, pressure, and the nozzle area in real time.

Fig. 3 shows a schematic of the experimental setup. The combustor is symmetrical and has a rectangular cross section. The fuel is room-temperature kerosene RP3, the jet is vertically sprayed, and the cavity structure is used for flame stabilization. There are two fuel jet positions, fuel jet P1 and fuel jet P3, as shown in Fig. 1. An electric spark was used to fire the hydrogen-assisted ignition. 


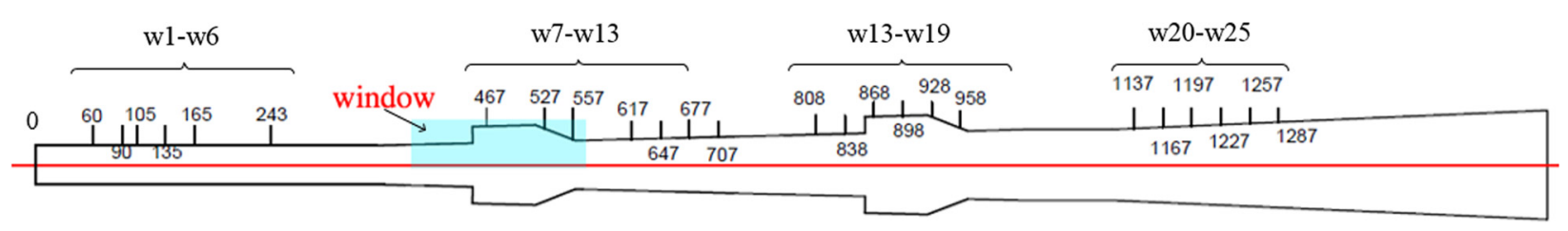

Fig. 3. Arrangement of pressure sensor and window.

Table 2

Experimental parameters for fixed equivalence ratio.

\begin{tabular}{lllll}
\hline Case & Ma & $\mathrm{T}_{\mathrm{t}}(\mathrm{K})$ & $\varphi 1$ & $\varphi 3$ \\
\hline $\mathrm{A} 1$ & $2.39-2.94$ & $1230-1683$ & 0.2 & 0.65 \\
\hline
\end{tabular}

\subsection{Measuring equipment}

Wall pressure is measured on the top walls using a DTC Initium ESP-32HD electronic pressure scanning module with 100 PSI range. As shown in Fig. 3, pressure sensors are located at points w1-w25. The number on or under measuring point is distance $(\mathrm{mm})$ from scramjet inlet.

$\mathrm{CH}^{*}$ observations window are performed in the first cavity, as shown in Fig. 3. A Phantom V1612 high-speed camera was used in the experiment. The $\mathrm{CH}^{*}$ frame rate was $20000 \mathrm{fps}$ and exposure time was $10 \mu \mathrm{s}$.

The kerosene flow was measured using an OMEGA 1300 series turbine flowmeter with accuracy of $1 \%$. The thrust was measured using an OMEGA LC203-500 load cell. All the measuring time was synchronized with the experimental time.

\subsection{One-dimensional method}

Three assumptions are used in the combustion chamber control equation in this study: (1) the flow is a one-dimensional steady flow, (2) the gas is thermally complete gas, and (3) the combustion chamber wall is an adiabatic wall.

The detailed calculation model has been introduced in a previous study [21]. Intense chemical reactions occur in a scramjet, and the static temperature ranges from $\sim 300 \mathrm{~K}$ in the inlet to $2000 \mathrm{~K}$ or higher in the combustion chamber; therefore, the influence of variable specific heat should be considered. The thermochemical composition database is used to calculate the variable specific heat. The solution of the equation adopts the space propulsion method, and $d x=0.001 \mathrm{~m}$ is set. Accuracy verification can ensure the accuracy and stability of the solution.

\section{Experimental results}

\subsection{Fixed equivalent ratio}

Variable Mach number experiments with constant equivalent ratios are analyzed as shown in Table 2 and Fig. $4 . \varphi 1$ and $\varphi 3$ are the equivalent ratios for the first and second cavities, respectively (fuel jet P1 and P3).

The ram-to-scram mode transition occurred in the first cavity, as clearly seen from the one-dimensional analysis (Fig. 5 left) and combustion flame state (Fig. 8); the second cavity is still in the ram mode. Fig. 5 (right) shows the distribution curve of the pressure ratio along the path, which varies with the inlet flow Mach number. The inlet flow Mach number changes continuously along the direction of the red arrow, and the curve density represents the gradient of pressure ratio change. In the figure, the curve for the first cavity is distributed unevenly, corresponding to the onedimensional analysis result curve (Fig. 5 left), and mode transition occurs in the first cavity. Between the first and second cavities, the pressure ratio is unevenly distributed along the direction of the

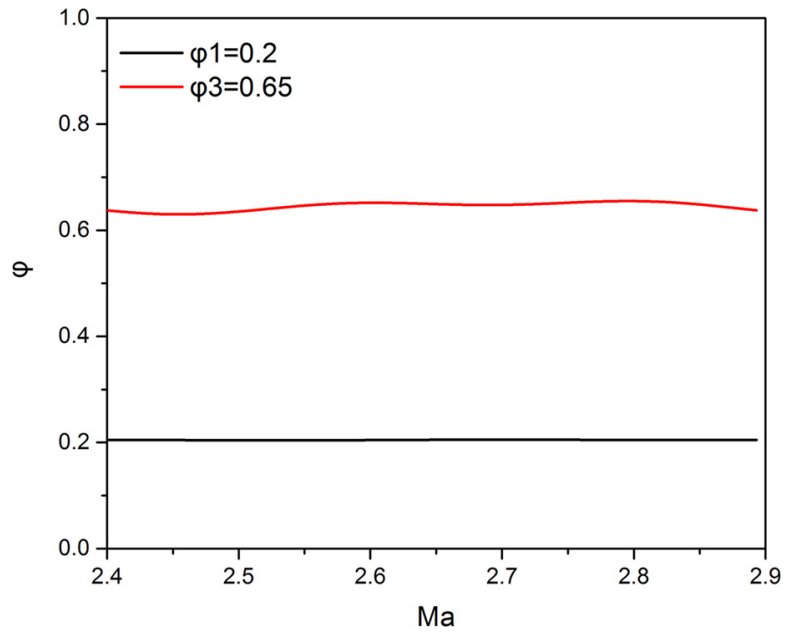

Fig. 4. Variation of equivalence ratio with continuously changing inlet flow Mach number.

engine, and a shock wave train compresses the gas and reduces the airflow velocity to form a ram mode in the second cavity. This is due to the relationship between the total combustion heat release and the combustor configuration. In the design, when the total equivalent ratio exceeds 0.8 and the combustion efficiency is up to $80 \%$, a thermal throat can form in the second cavity.

Fig. 6 (left) shows the pressure change with the inlet flow Mach number. The pressure distribution reflects the fuel heat release distribution, and the pressure change reflects the mode transition process. Two steps appear in the pressure in this figure, illustrating the instability in the mode transition. The two mutations of the first and second cavities are completely reversible, indicating that the mode transition process is unstable, however, the two cavities have a stabilizing effect on the combustion chamber. Fig. 6 (right) shows the continuous change in thrust, which represents the engine performance, indicating that the dual-injection combustion system makes the thrust stable.

To clarify the relationship between the pressure change and the flame during the experiment, Fig. 7 shows the $\mathrm{CH}^{*}$ luminescence intensity curve at the position of the first cavity with inlet flow Mach number during the dynamic experiment. The blue curve is the integral of the gray picture recorded by the camera at the first cavity, which can represent the relative intensity of the instantaneous flame $\mathrm{CH}^{*}$ luminescence. The red curve is the trend line of the blue curve. Two steps are seen between Ma 2.5 and 2.7; these are consistent with the moment of pressure point mutation. The luminescence intensity amplitude represents the heat release intensity amplitude. The average luminous intensity fluctuates greatly, and it reflects the large change in flame heat release. Large flame fluctuation in the transition zone indicates the instability of the mode transition process.

Fig. 7 is divided into three parts to analyze the flame morphology. $R_{A}, D_{A}$, and $S_{A}$ correspond to the ram mode, transition mode, and scram mode, respectively, in Case A1. These three modes correspond to three average flame forms, as shown in the pseudocolor image obtained by processing the average grayscale image in Fig. 8. 

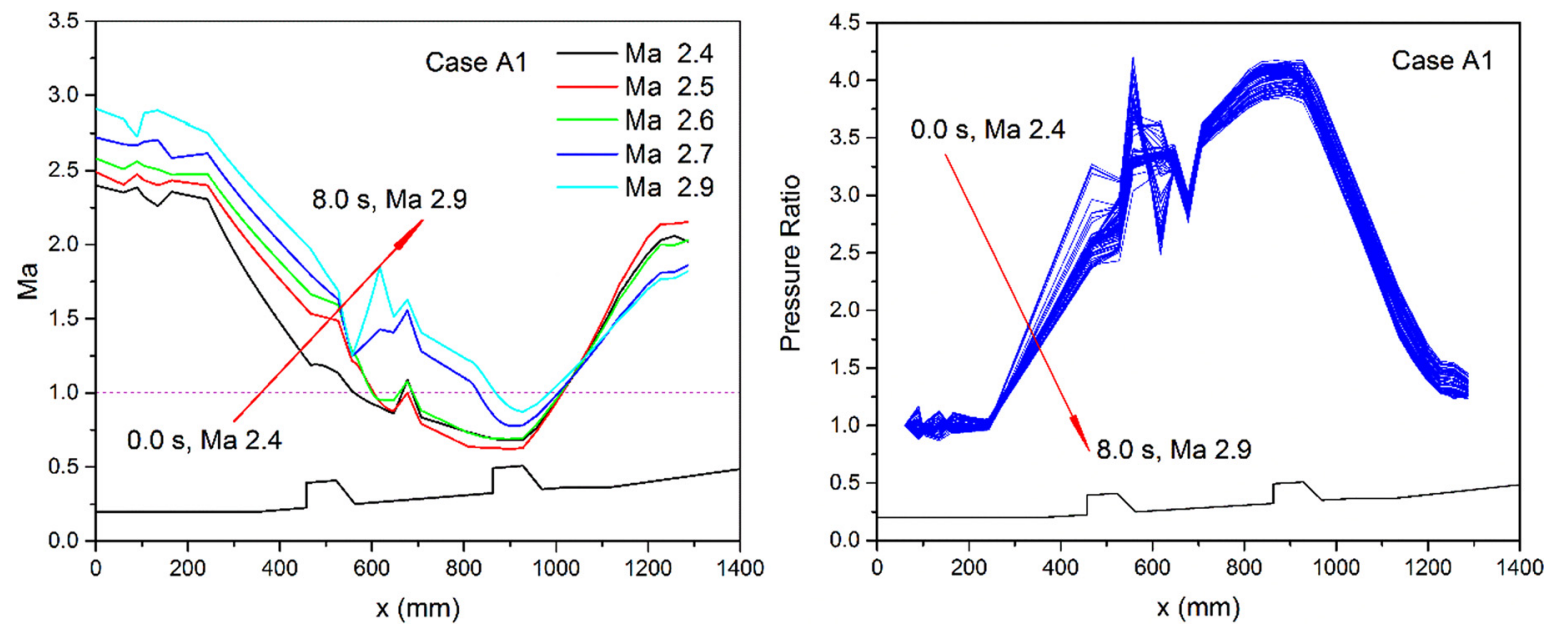

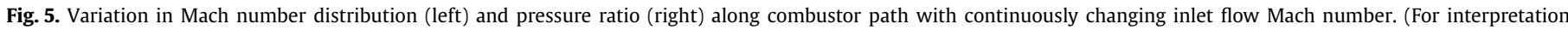
of the colors in the figure(s), the reader is referred to the web version of this article.)


Fig. 6. Pressure (left) and thrust (right) curves with continuously changing inlet flow Mach number

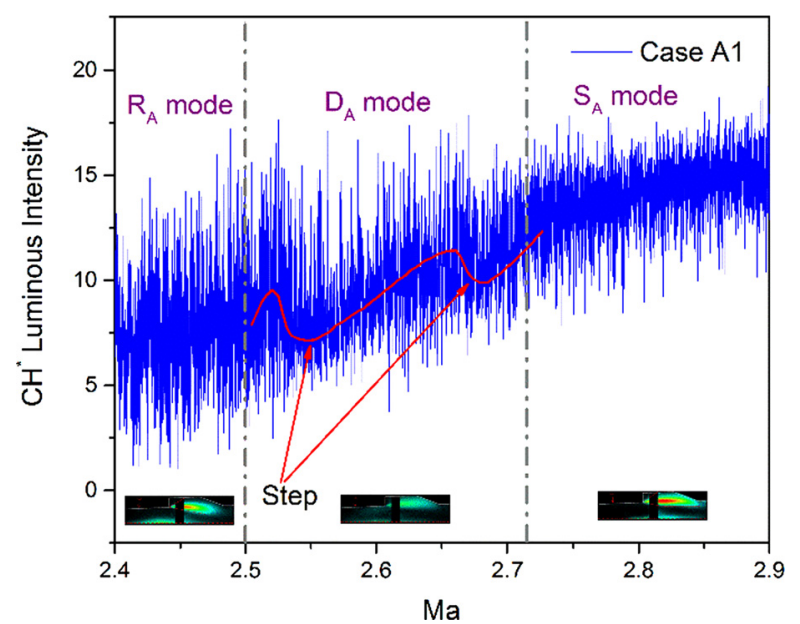

Fig. 7. Variation in $\mathrm{CH}^{*}$ luminescence intensity with inlet flow Mach number.

Fig. 9 shows the typical instantaneous flame morphology with different combustion modes. The $\mathrm{R}_{\mathrm{A}}$ mode is a typical stable flame form at low Mach number. The $S_{A}$ mode is a typical stable flame form at high Mach number. The $D_{A}$ mode is a type of transition state that contains a variety of $\mathrm{D}_{\mathrm{A}}$ mode flame forms $-\mathrm{D}_{\mathrm{A} 1}, \mathrm{D}_{\mathrm{A} 2}$, $\mathrm{D}_{\mathrm{A} 3}$, and $\mathrm{D}_{\mathrm{A} 4}$-as shown in Fig. 9. The cavity shear layer flame, jet flame, and two flame forms can coexist or appear independently.
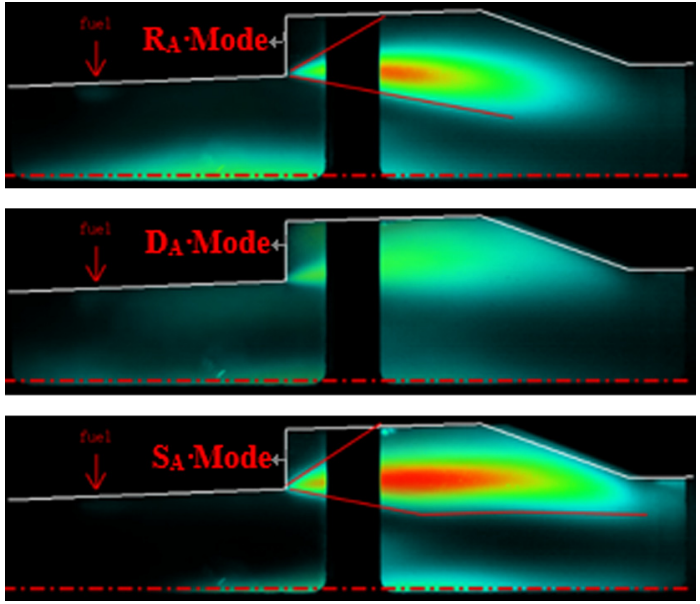

Fig. 8. Average images of three different combustion modes in dynamic process.

\subsection{Continuously changing equivalent ratio}

The previous analysis shows that the second cavity position is limited by the inlet flow Mach number range of the facility (Ma 1.7-3.0) and cannot complete mode transition at a fixed total equivalent ratio of 0.85 . To clarify the mode transition process, the equivalent ratio of the second cavity is reduced, and the first cav- 

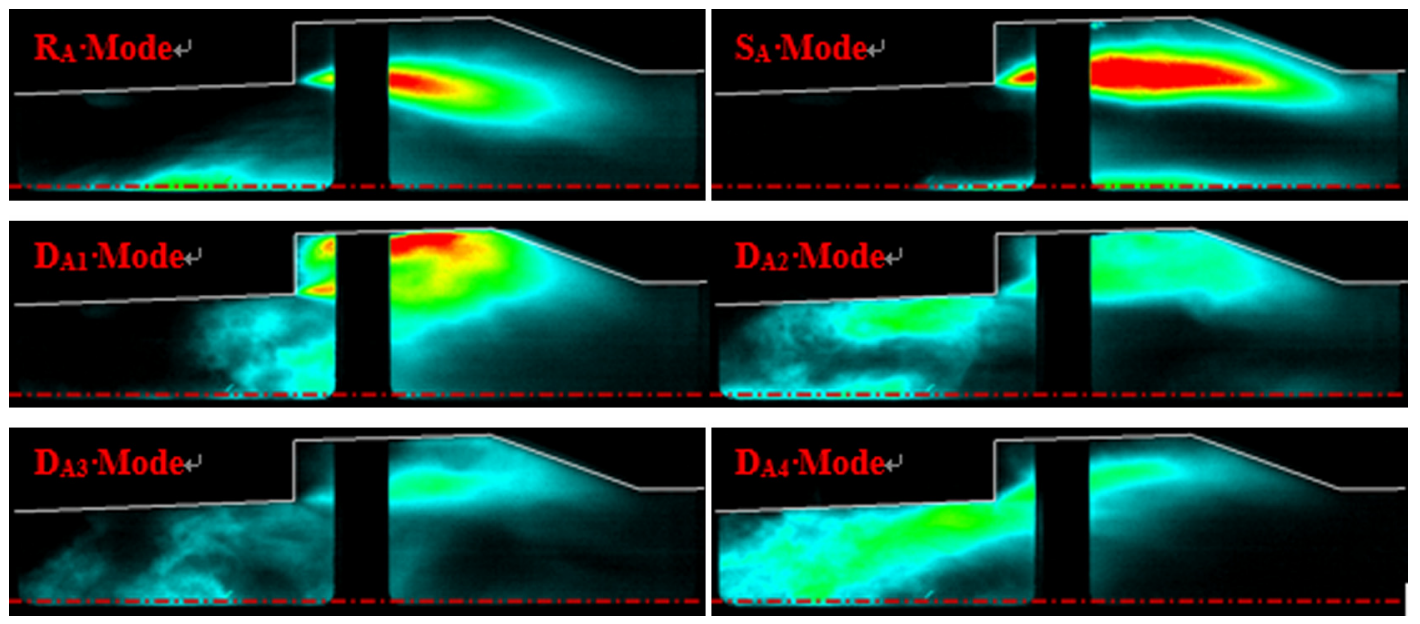

Fig. 9. Instantaneous images of three different combustion modes in dynamic process.

Table 3

Experimental parameters for continuously changing equivalence ratio.

\begin{tabular}{lllll}
\hline Case & Ma & $\mathrm{T}_{\mathrm{t}}(\mathrm{K})$ & $\varphi 1$ & $\varphi 3$ \\
\hline B1 & $2.42-2.96$ & $1237-1728$ & 0.3 & $0.6-0.22$ \\
\hline
\end{tabular}

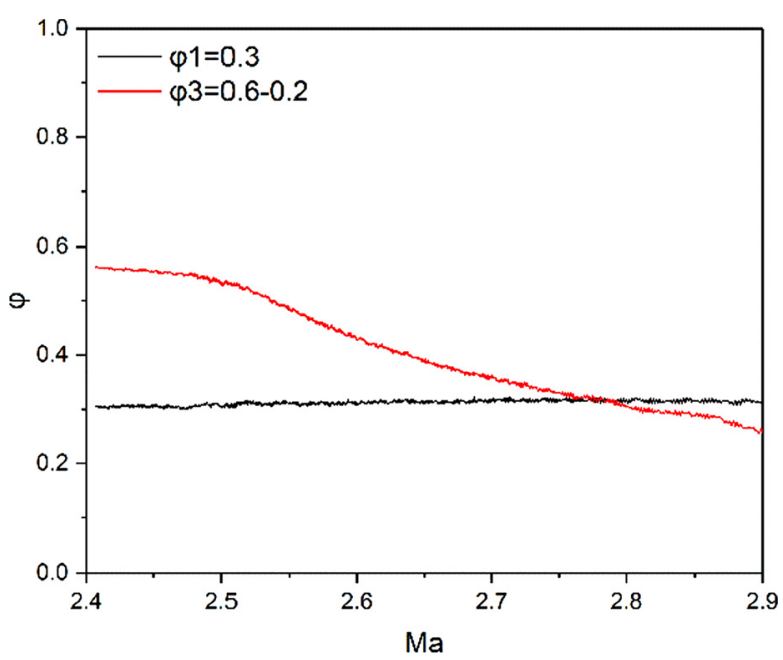

Fig. 10. Variation in equivalence ratio with different Mach numbers.

ity is basically stable with higher equivalent ratio than in Case A1 to improve the mode transition process here. Table 3 and Fig. 10 show equivalent ratios $\varphi 1$ and $\varphi 3$ of the first and second cavities, respectively (fuel jet P1 and P3). The kerosene equivalence ratio is maintained at $\sim 0.3$ at the first cavity $(\varphi 1)$, and that at the second cavity $(\varphi 3)$ is gradually decreased from 0.6 to 0.22 .

One-dimensional results of the Mach number (Fig. 11 left) indicate that the first cavity is in the ram mode for Ma 2.4-2.5. Currently, the overall equivalent ratio is relatively high. The pressure ratio curve (Fig. 12 right) shows that the combustor back pressure is pushed forward to the isolator. The transition point for the scram mode is between Ma 2.5 and 2.6, and a typical scram mode is seen for Ma 2.9. The average Mach number of the combustor increases when the downstream fuel is reduced, especially for Ma $>$ 2.9. The minimum Mach number of the combustor is slightly lower than 1.0. This is related to the change in the downstream equivalence ratio and the inlet flow Mach number.

The pressure ratio curve (Fig. 11 right) at the position of the first cavity has two relatively sparse parts, indicating that these two parts have a large rate of change. Corresponding to the one- dimensional analysis diagram, these can be considered positions where mode transition occurs. Along the direction of the red arrow, the first sparse position is the moment when the mode transitions from ram mode to transition mode, and the second sparse position is the moment when the mode transitions from transition mode to scram mode.

Fig. 12 shows that both the pressure and the thrust fluctuate greatly during mode transition. In particular, they decrease significantly between Ma 2.57 and 2.6. This is expected because the equivalence ratio decreases and Mach number increases. However, the descending slope shows a great change, indicating a large and abrupt change in the mode transition process. Interestingly, the change in the equivalent ratio of the second cavity location did not result in a local pressure mutation, whereas that of the first cavity location did. This is due to a more pronounced mode transition at the first cavity position than at the second cavity position.

For Ma $\sim 2.5$, large instability occurs. First, the pressure pulsation is relatively large, with amplitude exceeding $50 \mathrm{kPa}$. Combustor pressure fluctuation is caused by the change in the equivalent ratio and inlet flow Mach number. Unlike in the previous case, the thrust also fluctuates greatly in this case. This is because the instability is mainly caused by the position of the second cavity and cannot be eliminated in the combustor, thus showing the instability of the engine.

Fig. 13 shows that combustion heat release shows greater fluctuation in Case B1 than in Case A1. Steps corresponding to the pressure are also seen. For Ma $>2.6$, upstream combustion occurs in the scram mode and becomes relatively stable. This is because the mix gradually becomes the main factor controlling combustion, and Mach cone formation limits the propagation of disturbance with increasing Mach number.

Case B1 can also be divided into three combustion modes. However, because the flame morphology is different from that in Case $\mathrm{A} 1$, it is defined as $R_{\mathrm{B}}, D_{\mathrm{B}}$, and $S_{\mathrm{B}}$. The average flame in Fig. 14 shows that the $R_{\mathrm{B}}$ mode is also a type of shearing layer flame. However, the transient flame form (Fig. 15) shows that combustion is unstable; this is why we have redefined it as $R_{\mathrm{B}}$ mode. The $D_{\mathrm{B}}$ mode is a very unstable state and the flame is in the shear layer; however, it is closer to the bottom of the cavity, and the flame is nearly extinguished at its lowest intensity. The $S_{B}$ mode is similar to the $S_{\mathrm{A}}$ mode in case A1; however, its stability is poorer and there is a large degree of dispersion that is caused by the variable equivalent ratio in the second cavity.

The analysis of these two examples shows that for the mode transition process, a mutation occurs in the transitions from both the ram mode to the transition mode and the transition mode to the scram mode. For two-stage fuel injection systems, mutations 



Fig. 11. Variation in Mach number distribution (left) and pressure ratio (right) along combustor path with continuously changing inlet flow Mach number.
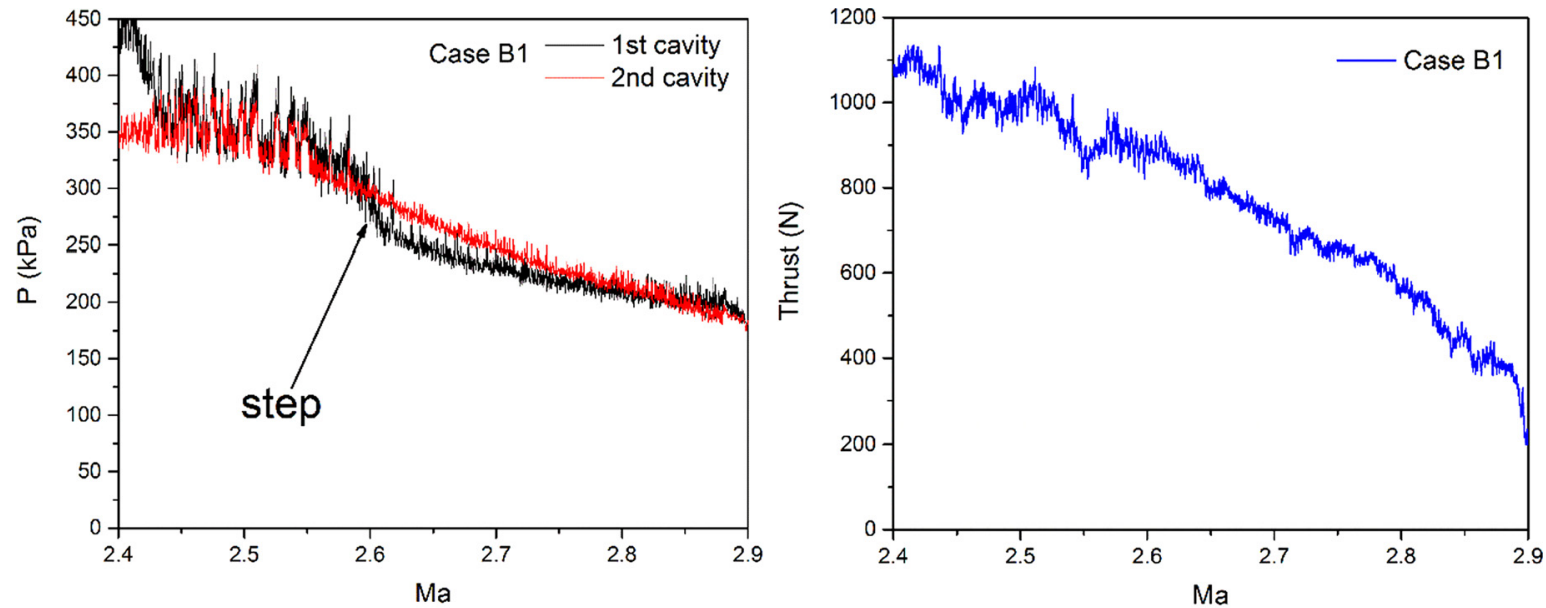

Fig. 12. Variation in pressure (left) and thrust (right) with continuously changing inlet flow Mach number.

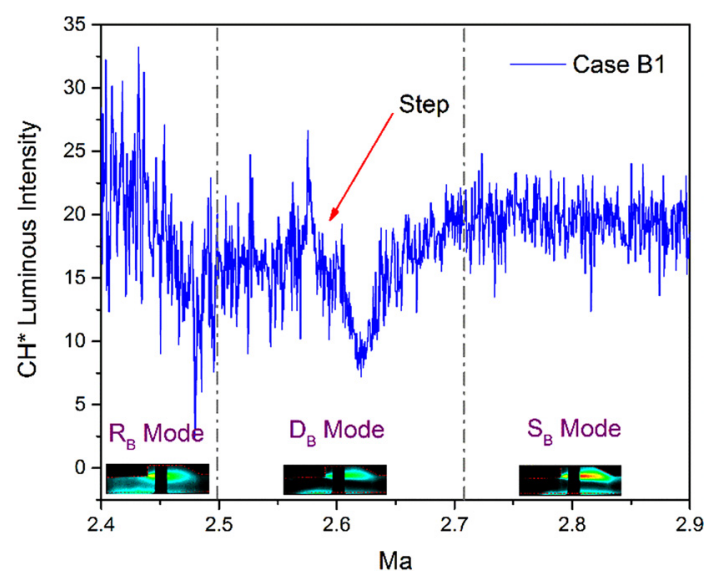

Fig. 13. Variation in $\mathrm{CH}^{*}$ luminescence intensity with inlet flow Mach number.

are conditional. The thrust in Case A1 has no mutation, that is, the whole system is stable. If the system as a whole is in transition, the thrust changes suddenly.

\section{Conclusion}

For the first time, continuous acceleration under nearly constant dynamic pressure was realized in a scramjet combustor and the mode transition process was demonstrated. Experiments with
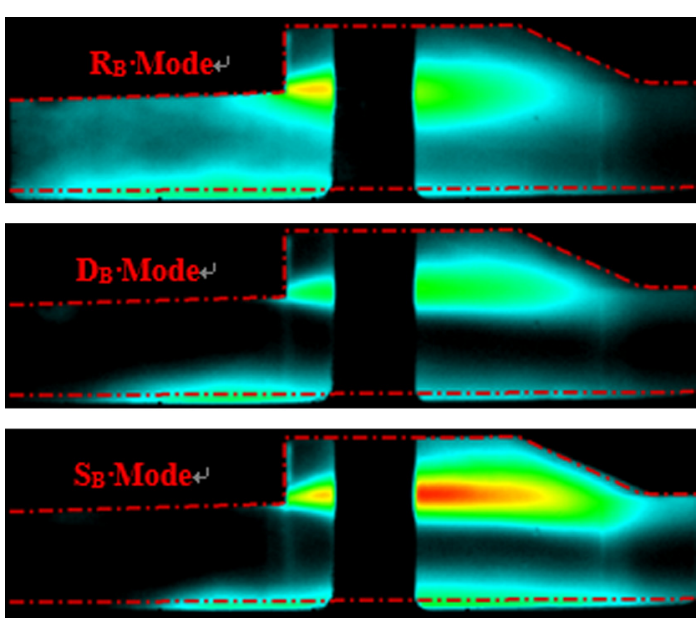

Fig. 14. Average images of three different combustion modes in dynamic process.

constant and continuously decreasing equivalent ratio were conducted.

Mode transition was demonstrated experimentally in the cavity structure of the combustor using a room-temperature kerosene vertical jet. In the ram mode, the flame is mainly stabilized in the jet wake or cavity shear layer. In the transition mode, the flame 

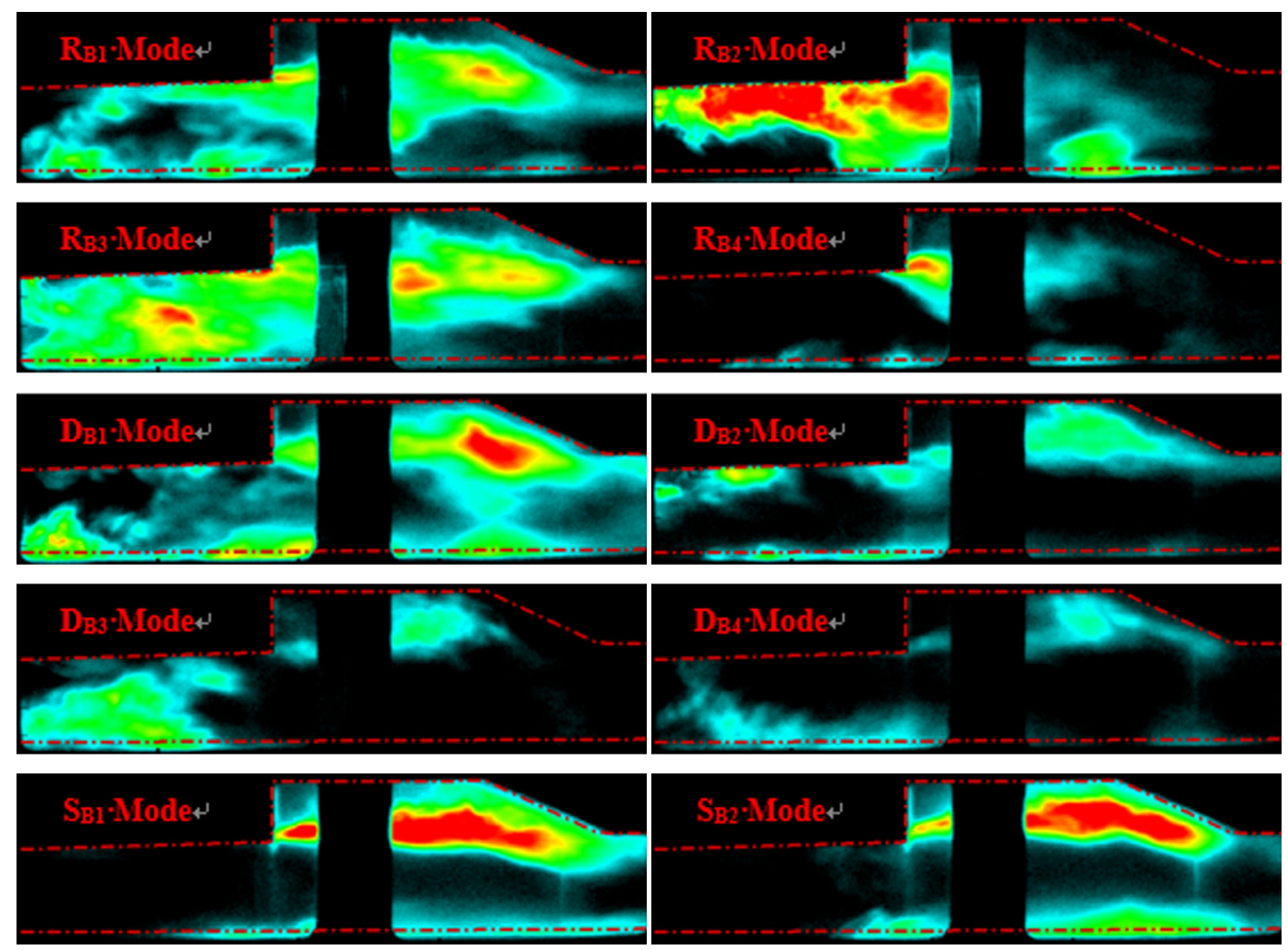

Fig. 15. Instantaneous images of three different combustion modes in dynamic process.

oscillates between the jet wake and the cavity shear layer. In the scram mode, the flame only exists in the cavity shear layer.

For an independent mode transition process, the transition from both the ram mode to the transition mode and from the transition mode to the scram mode are unstable. The pressure pulsation amplitude increases and abrupt changes in thrust occur. For two-stage systems (with two jet points and flame stability zones), the system stability is determined by the overall engine state. If the engine is in the ram mode, irrespective of the mode in the first cavity, it is basically stable, and the instability is eliminated by the second cavity or thermal throat. If the whole engine is in a transient mode, the mode transition in the first cavity will cause instability.

Basically, the instability of the mode transition is related to the flame mode. The transition from the ram mode to the scram mode involves a change in the flame propagation characteristics. If there is a large change in the combustion mode, it must be unstable. In this experiment, the transition from the ram mode to the scram mode is a transition from jet flame stability to cavity shear layer flame stability.

\section{Declaration of Competing Interest}

The authors declare no conflict of interest.

\section{Acknowledgements}

The work is partially supported by National Natural Science Foundation of China (Grant Nos. 11772342). The authors acknowledge the technical assistance provided by the technicians at the Institute of Mechanics, Chinese Academy of Sciences.

\section{References}

[1] F.S. Billig, G.L. Dugger, The interaction of shock waves and heat addition in the design of supersonic combustors, Symp. (Int.) Combust. 12 (1969) 1125-1139, https://doi.org/10.1016/S0082-0784(69)80490-X.
[2] L. Tian, L.H. Chen, Q. Chen, F. Li, X.Y. Chang, Quasi-one-dimensional multimodes analysis for dual-mode scramjet, J. Propuls. Power 30 (2014) 1559-1567.

[3] W. Bao, Q.C. Yang, J.T. Chang, Y.H. Zong, J.C. Hu, Dynamic characteristics of combustion mode transitions in a strut-based scramjet combustor model, J. Propuls. Power 29 (2013) 1244-1248.

[4] Q.C. Yang, J.C. Hu, J.T. Chang, Y.H. Zong, W. Bao, Experimental study on combustion mode transition effects in a strut-based scramjet combustor, Proc. Inst. Mech. Eng., G J. Aerosp. Eng. 229 (2015) 764-771.

[5] C.P. Goyne, J.C. McDaniel, R.H. Krauss, W.B. Whitehurst, Test gas vitiation effects in a dual-mode scramjet combustor, J. Propuls. Power 23 (2007) 559-565.

[6] R.D. Rockwell, C.P. Goyne, W. Haw, R.H. Krauss, J.C. McDaniel, C.J. Trefny, Experimental study of test-medium vitiation effects on dual-mode scramjet performance, J. Propuls. Power 27 (2011) 1135-1142.

[7] T. Kouchi, G. Masuya, T. Mitani, S. Tomioka, Mechanism and control of combustion-mode transition in a scramjet engine, J. Propuls. Power 28 (2012) $106-112$

[8] G.A. Sullins, Demonstration of mode transition in a scramjet combustor, J. Propuls. Power 9 (1993) 515-520.

[9] D.J. Micka, J.F. Driscoll, Combustion characteristics of a dual-mode scramjet combustor with cavity flameholder, Proc. Combust. Inst. 32 (2009) 2397-2404, https://doi.org/10.1016/j.proci.2008.06.192.

[10] Y.M. Yuan, T.C. Zhang, W. Yao, X.J. Fan, P. Zhang, Characterization of flame stabilization modes in an ethylene-fueled supersonic combustor using time-resolved $\mathrm{CH}^{*}$ chemiluminescence, Proc. Combust. Inst. 36 (2017) 2919-2925, https:// doi.org/10.1016/j.proci.2016.07.040.

[11] W. Huang, Z.B. Du, L. Yan, R. Moradi, Flame propagation and stabilization in dual-mode scramjet combustors: a survey, Prog. Aerosp. Sci. 101 (2018) 13-30.

[12] Y. Yang, Z. Wang, Y. Zhang, M. Sun, H. Wang, Flame stabilization with a rearwall-expansion cavity in a supersonic combustor, Acta Astronaut. 152 (2018) 752-756, https://doi.org/10.1016/j.actaastro.2018.09.027.

[13] M.R. Gruber, R.A. Baurle, T. Mathur, K.Y. Hsu, Fundamental studies of cavitybased flameholder concepts for supersonic combustors, J. Propuls. Power 17 (2001) 146-153.

[14] Z. Cai, M. Sun, Z. Wang, X.-S. Bai, Effect of cavity geometry on fuel transport and mixing processes in a scramjet combustor, Aerosp. Sci. Technol. 80 (2018) 309-314, https://doi.org/10.1016/j.ast.2018.07.028.

[15] M.L. Fotia, Mechanics of combustion mode transition in a direct-connect ramjet-scramjet experiment, J. Propuls. Power 31 (2015) 69-78, https://doi.org/ 10.2514/1.B35171.

[16] C. Zhang, J. Chang, J. Ma, W. Bao, D. Yu, J. Tang, Effect of Mach number and equivalence ratio on the pressure rising variation during combustion mode transition in a dual-mode combustor, Aerosp. Sci. Technol. 72 (2018) 516-524, https://doi.org/10.1016/j.ast.2017.11.042. 
[17] C. Zhang, J. Chang, J. Zhang, W. Bao, D. Yu, Effect of continuous Mach number variation of incoming flow on ram-scram transition in a dual-mode combustor, Aerosp. Sci. Technol. 76 (2018) 433-441, https://doi.org/10.1016/j.ast.2018.02. 027.

[18] Z.P. Wang, F. Li, H.S. Gu, X.L. Yu, X.Y. Zhang, Experimental study on the effect of combustor configuration on the performance of dual-mode combustor, Aerosp. Sci. Technol. 42 (2015) 169-175.

[19] R.J. Yentsch, D.V. Gaitonde, Unsteady three-dimensional mode transition phenomena in a scramjet flowpath, J. Propuls. Power 31 (2015) 104-122.
[20] K.R. Jackson, M.R. Gruber, S. Buccellato, Mach 6-8+hydrocarbon-fueled scramjet flight experiment: the HIFiRE flight 2 project, J. Propuls. Power 31 (2015) 36-53, https://doi.org/10.2514/1.B35350.

[21] Z.P. Wang, H.B. Gu, L.W. Cheng, F.Q. Zhong, X.Y. Zhang, $\mathrm{CH}^{*}$ luminance distribution application and a one-dimensional model of the supersonic combustor heat release quantization, Int. J. Turbo Jet-Engines 36 (2019) 45-50, https:// doi.org/10.1515/tjj-2016-0064. 